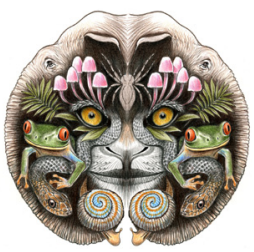

ISSN

Online 0974-7907

Print 0974-7893
Namdapha Gliding Squirrel Biswamoyopterus biswasi is one of the Critically Endangered (Molur 2008) and endemic gliding squirrels found in India. It is thought to inhabit the Mesua ferrea jungles bordering the Noa-Dihing River of Namdapha National Park (NNP),

Arunachal Pradesh, India. During our survey on gliding squirrel diversity in NNP, we confirmed the presence of the Red Giant Gliding Squirrel Petaurista petaurista (RGGS) and Parti-colored Gliding Squirrel Hylopetes alboniger through spotlighting and a specimen of the Spotted Giant Gliding Squirrel Petaurista elegans collected from this region is preserved at ZSI, Kolkata (specimen named as $P$. sybilla, Collection No. NM/30). However, we did not encounter Namdapha Gliding Squirrel (NGS) during our multiple surveys (6 field sessions including 120 survey nights). Its discovery in the 1980s (Saha 1981; De et al. 2006) is the only time when the species was originally studied (dead specimen) after which it has neither been sighted nor documented. However, many tourists, forest department personnel and researchers claim the documentation of the species, but no published record is available on the sightings of the species elsewhere. Before the start of our initial survey on gliding squirrels of NNP, we tried to gather information on the possible distribution of NGS through forest personnel (rangers, forest watchers and guards). However, during our multiple surveys in NNP we recorded RGGS in those areas which are thought to be occupied by NGS according to the forest personnel.

\section{Why the Red Giant GLIDING SQUiRREL PETAURISTA PETAURISTA IS OFTEN MISTAKEN FOR THE NAMDAPHA GLIDING SQUIRREL BISWAMOYOPTERUS BISWASI (MAMMALIA: RODENTIA: SCIURIDAE) IN NAMDAPHA National Park, Arunachal Pradesh, INDIA}

\section{Murali Krishna ${ }^{1}$ \& Awadhesh Kumar ${ }^{2}$}

1,2 Wildlife Resource \& Conservation Lab, Department of Forestry, North Eastern Regional Institute of Science and Technology (NERIST), Nirjuli, Arunachal Pradesh 791109, India ${ }^{1}$ murali7murali@gmail.com (corresponding author),

2tpileatus@gmail.com

We interacted with many of the tourists $(n=21)$, and researchers $(n=9)$ who have visited NNP and from those interactions, we realised that the majority of them mistake RGGS as NGS. So, based on those interactions, we concluded many reasons behind the ignorance of people towards the identification of the species, some of which are listed below:

(i) S.S. Saha described the species NGS in the year 1981 and the data regarding the species pelage colour and original photographs of it are documented only in the paper published by the Bulletin of Zoological Survey of India which is not available online because the paper is often not in circulation (Image 1). Also, many other papers which provide the description of NGS are not often under circulation (Choudhury 2009). The holotype is preserved at ZSI, Kolkata; no other voucher specimens occur elsewhere (Image 2).

DOI: http://dx.doi.org/10.11609/JoTT.03727.6138-41 | ZooBank: urn:Isid:zoobank.org:pub:F7794CAB-B03F-431C-AFAA-B77D6BDD298F

Editor: Anwaruddin Chowdhury, Guwahati, India.

Date of publication: 26 July 2014 (online \& print)

Manuscript details: Ms \# 03727 | Received 30 July 2013 | Final received 06 May 2014 | Finally accepted 08 July 2014

Citation: Krishna, C.M. \& A. Kumar (2014). Why the Red Giant Gliding Squirrel Petaurista petaurista is often mistaken for the Namdapha Gliding Squirrel Biswamoyopterus biswasi (Mammalia: Rodentia: Sciuridae) in Namdapha National Park, Arunachal Pradesh, India. Journal of Threatened Taxa 6(8): 6138-6141; http://dx.doi. org/10.11609/JoTT.03727.6138-41

Copyright: @ Krishna \& Kumar 2014. Creative Commons Attribution 4.0 International License. JoTT allows unrestricted use of this article in any medium, reproduction and distribution by providing adequate credit to the authors and the source of publication.

Funding: The equipments for the project were funded by IdeaWild Grant, USA.

Competing Interest: The authors declare no competing interests.

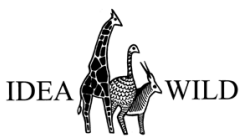

Acknowledgements: We thank the Principal Chief Conservator of Forest (Wildlife \& Biodiversity), Arunachal Pradesh and the Field Director and Research Officer of Namdapha National Park for granting us permission to carry out the survey. Also, we thank the Director, Dr. Gaurav Sharma and Dr. Gopinathan Maheswaran of ZSI, Kolkata for allowing us to study and photograph the gliding squirrel specimens. Kamalakaran, ZSI Kolkata is also thanked for guiding us through the gliding squirrel specimens. We are grateful to IdeaWild Grant, USA for the equipment support. Lastly we thank Bironjay Basumatary, Erebo Chakma, Tinku Chakma and Sambu Chakma for their assistance during the surveys. Also, we thank the reviewers for necessary comments that helped in building up this manuscript. 
(ii) Many websites on the internet often mistakenly present RGGS as NGS even "Arkive" sections included other gliding squirrel (possibly Hodgson's Gliding Squirrel) stating it to be NGS, which was later removed (Arkive 2010).

(iii) RGGS has nearly 5-10 subspecies and the variation of the pelage colour is observed (Corbet \& Hill 1992; Yu 2002) this could be one of the reasons behind the incorrect identification of the species. Moreover, both NGS and RGGS share similar habitats in NNP.

(iv) Endemism is the other reason behind the thought. As NGS is thought to be endemic to NNP in the state of Arunachal Pradesh, India (De et al. 2006) many people have a perception that the gliding squirrel found in NNP is NGS.

(v) The Indian mammal field guide by Menon (2003, 2014) though provides a photographic plate showing the head portion of NGS, the poor picture quality could be a reason for wrong identification of the same.

(vi) The specimen at Miao museum of Namdapha National Park cum Tiger Reserve holds a specimen of gliding squirrel named as NGS which actually is RGGS (Image 3). It was corrected as RGGS only in early 2012 after our suggestion.

Thus, we thought to provide important information regarding the morphological characters of NGS with

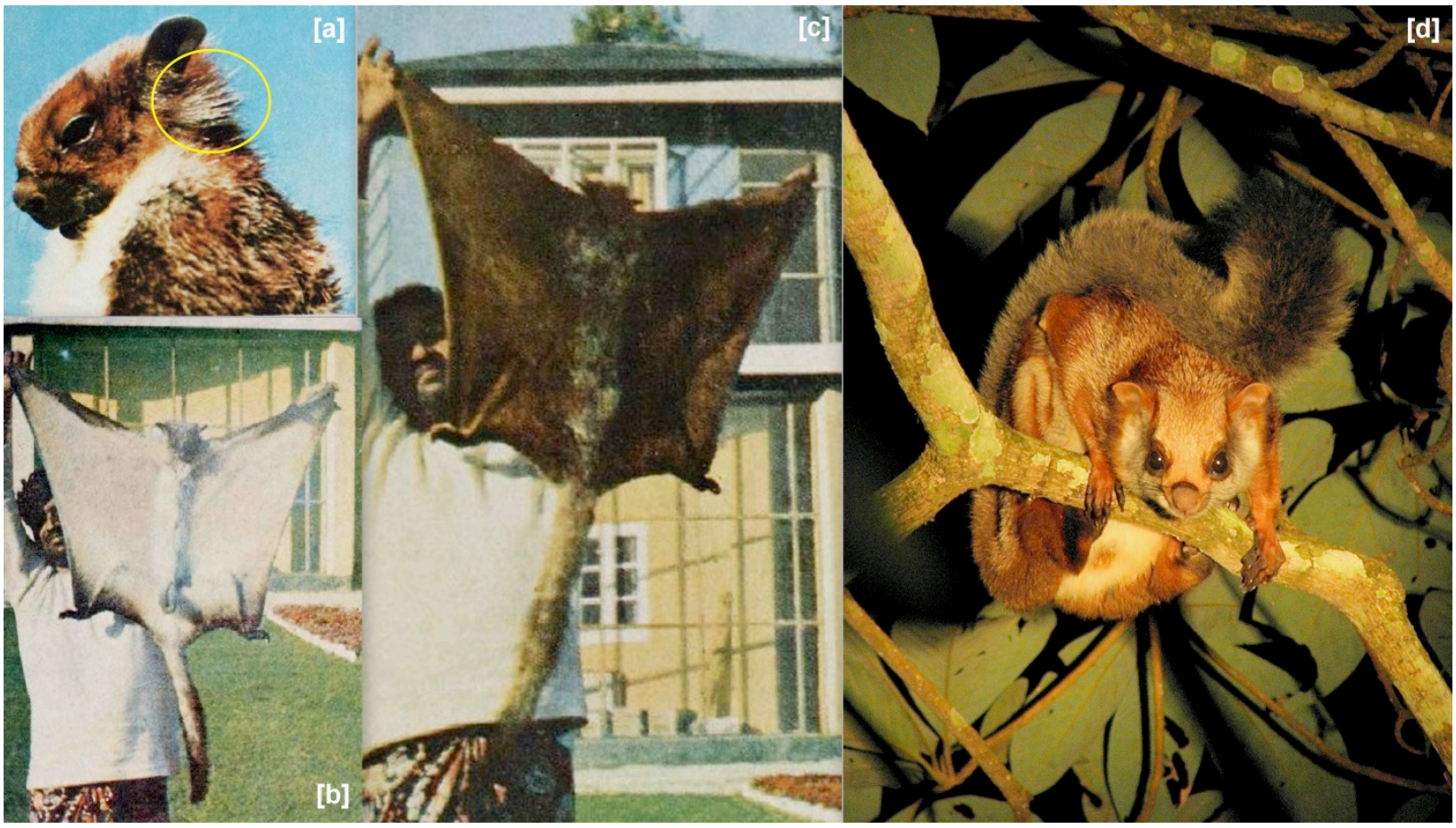

Image 1. $[a, b, c]$ Showing the head, dorsal and ventral portion of Namdapha Gliding Squirrel Biswamoyopterus biswasi (@ S.S. Saha) (Saha, 1981) (yellow circle showing the white coloured ear tufts in figure [a]); [d] Showing the picture of Red Giant Gliding Squirrel Petaurista petaurista (@ C. Murali Krishna)

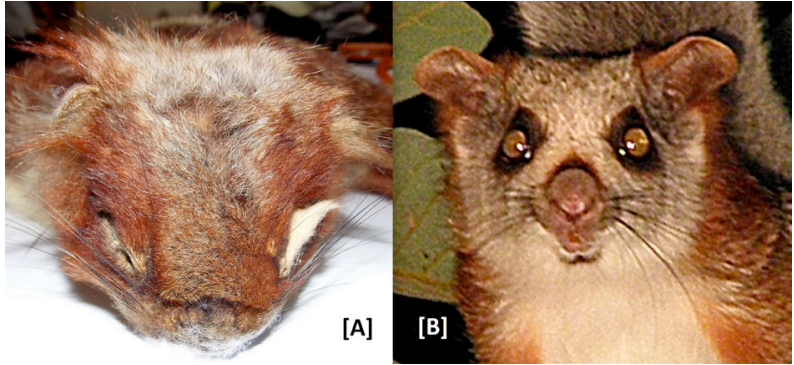

Image 2. Comparative account of the head portion (front side) A - Namdapha Gliding Squirrel (photographed from ZSI, Kolkata); B - Red Giant Gliding Squirrel (@ C. Murali Krishna)

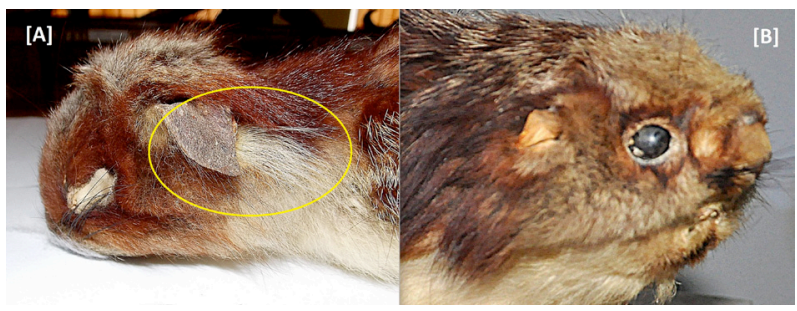

Image 3. Comparative account of head portion (sidewise). A - NGS (Yellow portion highlighting the ear tufts) (photographed from ZSI, Kolkata); B - RGGS (Photographed from NNP Museum at Miao). 
Table 1. Comparison of morphological characteristics of Namdapha Gliding Squirrel and Red Giant Gliding Squirrel

\begin{tabular}{|c|c|c|c|}
\hline & Morphological characters & Namdapha Gliding Squirrel Biswamoyopterus biswasi & $\begin{array}{l}\text { Red Giant Gliding Squirrel } \\
\text { Petaurista petaurista candidula* }\end{array}$ \\
\hline 1. & Total Body Length & $1010 \mathrm{~mm}$ & $1150 \mathrm{~mm}$ \\
\hline 2. & Head \& Body & $405 \mathrm{~mm}$ & $520 \mathrm{~mm}$ \\
\hline 3. & Hind Foot & $78 \mathrm{~mm}$ & $75-100 \mathrm{~mm}$ \\
\hline 4. & Tail & $605 \mathrm{~mm}$ & $630 \mathrm{~mm}$ \\
\hline 5. & Pelage Colour & Body above is morocco red grizzled with white & $\begin{array}{l}\text { Body above is partially morocco red grizzled with white } \\
\text { dominated by greyish and blackish }\end{array}$ \\
\hline 6. & Crown Colour & Grey hair tipped with red & White intermixed with black hair \\
\hline 7. & Tail colour & $\begin{array}{l}\text { parti-coloured and beyond the inter-femoral membrane } \\
\text { proximally pale smoky gray changing distally to vinaceous } \\
\text { rufous and then to clove brown coloured near tip }\end{array}$ & $\begin{array}{l}\text { Greyish beyond the inter-femoral membrane and then to } \\
\text { black coloured near tip }\end{array}$ \\
\hline 8. & Facial markings & $\begin{array}{l}\text { Red coloured circles around eyes and narrow black lines } \\
\text { forming nasal bridge }\end{array}$ & $\begin{array}{l}\text { Prominent Red coloured circles intermixed with black } \\
\text { around eyes followed by black markings above the nose } \\
\text { and below the chin. }\end{array}$ \\
\hline 9. & Patagium & Ventral side washed with faint orange-rufous & Ventral side with white hair \\
\hline 10. & Edges of Patagium & Red colour & Ashy colour \\
\hline 11. & Ear tufts & $\begin{array}{l}\text { Distinct White ear tufts with silvery white margins on the } \\
\text { posterior side but the anterior margins basally }\end{array}$ & No such ear tufts are present \\
\hline 12. & Ventral Body Colouration & White with hairs with pearly grey bases & Pure white coat \\
\hline
\end{tabular}

* Of the 5-10 subspecies of Petaurista petaurista, P. p. candidula is the subspecies that is observed in Namdapha National Park.

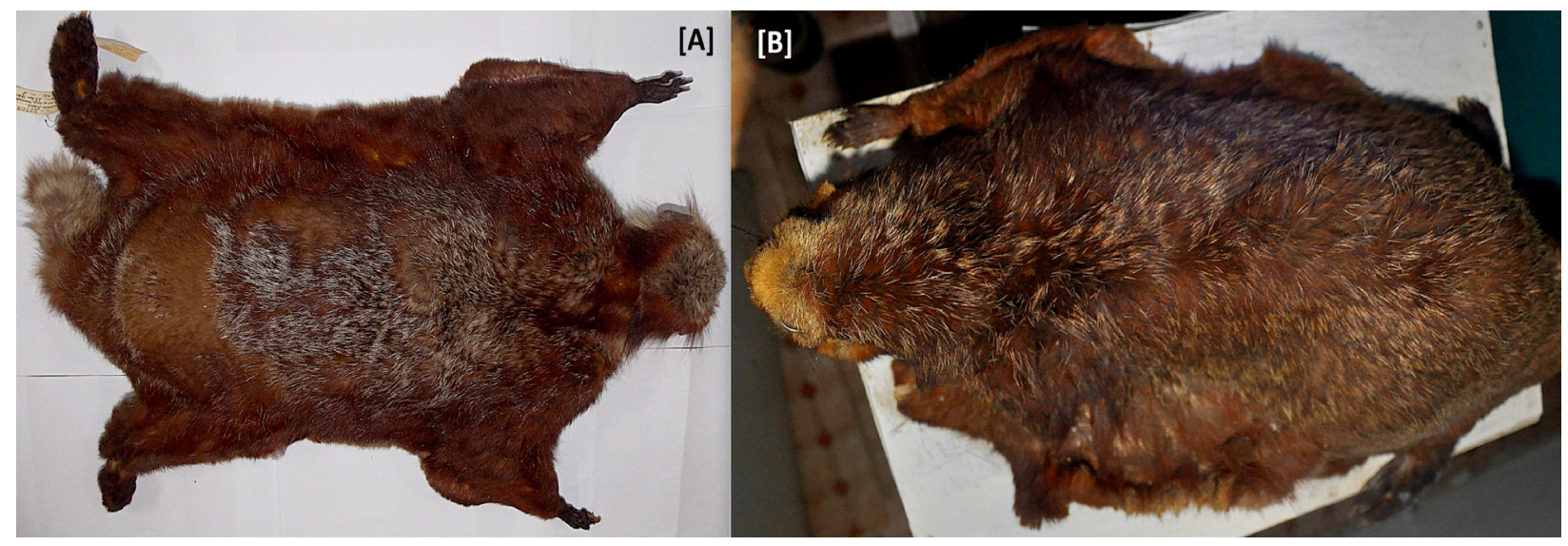

Image 4. Comparative account of dorsal portion. A - NGS (photographed from ZSI, Kolkata); B - RGGS (photographed from NNP Museum at Miao).

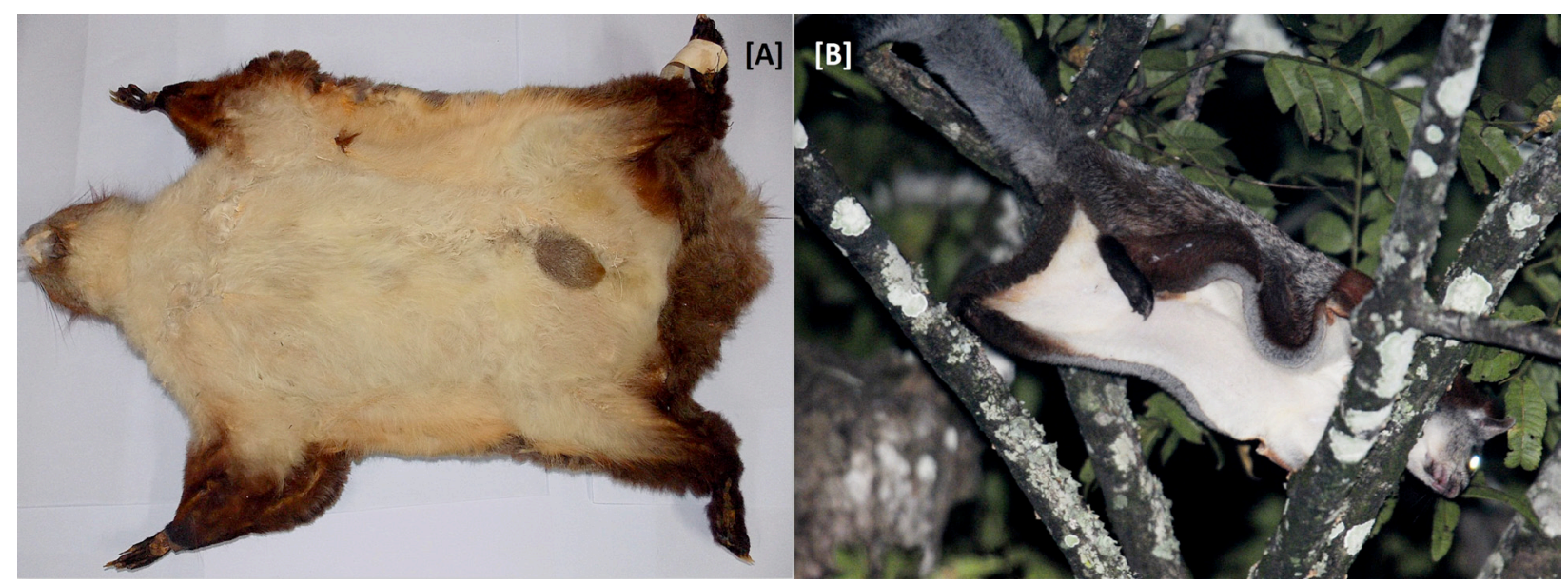

Image 5. Comparative account of ventral portion. A - NGS (Photographed from ZSI, Kolkata); B - RGGS (C Ranjan Kumar Das) 


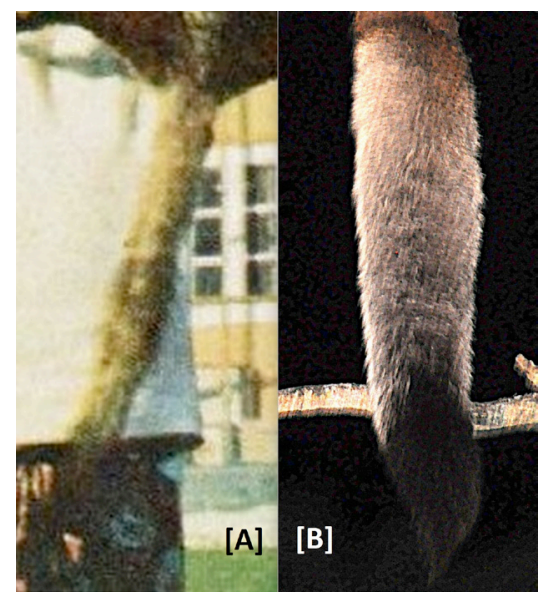

Image 6. Comparative account of tails. A - NGS (@ S.S. Saha) (Saha, 1981); B - RGGS (@ C. Murali Krishna)

photographs from published works, which will help in identification of the species (Images 4-6).

Morphological characteristics of Namdapha Gliding Squirrel Biswamoyopterus biswasi as described by Saha (1981), Choudhury (2009) and Thorington et al. (2012) are presented in Table 1.

Of the above mentioned characteristics, the presence of the white coloured ear tufts is the main differentiating character of NGS from RGGS, also, the adult individual of NGS is smaller in size when compared to RGGS (Total Body length: $1150 \mathrm{~mm}$ ).

\section{References}

Arkive (2010). http://www.arkive.org/namdapha-gliding-squirrel/ biswamoyopterus-biswasi/ Downloaded on 20 September 2010

Choudhury, A. (2009). One more new species of Giant Flying Squirrel of the Genus Petaurista Link, 1795 from Arunachal Pradesh in north-east India. Newsletter and Journal of the Rhino Foundation for nature in NE India 8: 26-34.

Corbet, G.B. \& J.E. Hill (1992). The Mammals of the Indo-Malayan Region: A Systematic Review. Oxford University Press, Oxford, United Kingdom, 307-314pp.

De, J.K., A.K. Mandal \& M.K. Ghosh (2006). Mammals. Bulletin of Zoological Survey of India. Fauna of Arunachal Pradesh, State Series 13(1): 21-68.

Menon, V. (2003). A Field Guide to Indian Mammals. Dorling Kindersley (India) Pvt. Limited and Penguin Book India (P) Ltd, New Delhi, 200pp.

Menon, V. (2014). Indian Mammals: A Field Guide. Hachette India, New Delhi, 528pp

Molur, S. (2008). Biswamoyopterus biswasi. In: IUCN 2013. IUCN Red List of Threatened Species. Version 2013.2. <www.iucnredlist.org>. Downloaded on 06 May 2014.

Saha, S.S. (1981). A new genus and new species of flying squirrel (Mammalia: Rodentia: Scuiridae) from northeast India. Bulletin of Zoological Survey of India 4(3): 331-336.

Thorington, R.W. Jr., J.L. Koprowski, M.A. Steele \& J.F. Whatton (2012). Squirrels of the World. Johns Hopkins University Press, Baltimore, Maryland, 459

Yu, F. (2002). Systematics and biogeography of flying squirrels in the eastern and the western trans-Himalayas. A dissertation presented to the graduate school of the University of Florida in partial fulfilment of the requirements for the degree of doctor of philosophy. University of Florida. 